\title{
Non-celiac gluten hypersensitivity: What is all the fuss about? Steffen Husby ${ }^{*}$ and Joseph Murray ${ }^{2}$
}

\author{
Addresses: ${ }^{1}$ Hans Christian Andersen Children's Hospital, Odense University Hospital, 29 Sdr. Boulevard, DK-5000 Odense C, Denmark; \\ ${ }^{2}$ Division of Gastroenterology and Hepatology, Mayo Clinic, 200 1st St SW, Rochester, MN 55905, USA \\ * Corresponding author: Steffen Husby (Steffen.Husby@rsyd.dk) \\ Fl000Prime Reports 2015, 7:54 (doi:10.12703/P7-54) \\ All FI000Prime Reports articles are distributed under the terms of the Creative Commons Attribution-Non Commercial License \\ (http://creativecommons.org/licenses/by-nc/3.0/legalcode), which permits non-commercial use, distribution, and reproduction in any medium, \\ provided the original work is properly cited. \\ The electronic version of this article is the complete one and can be found at: http://fl000.com/prime/reports/m/7/54
}

\begin{abstract}
Non-celiac gluten sensitivity (NCGS) has been introduced recently as a potentially common disease on the basis of studies of patients with claimed reactivity to gluten but without the characteristics of celiac disease (CD). CD is characterized by antibody reactivity toward the autoantigen transglutaminase 2, characteristic histological abnormalities of the small intestine, and an almost obligatory genetic haplotype (HLA-DQ2 or DQ8). The diagnosis of NCGS is based largely on the clinical suspicion of hyper-reactivity to gluten and the absence of the characteristics of CD. Few published studies have used double-blind placebo-controlled food challenges (DBPCFCs) for the diagnosis of NCGS, and none in children. Innate immune reactivity to amylase trypsin inhibitors has been suggested as the pathogenic principle in NCGS, but confirmatory evidence is lacking. Also, further clinical studies including DBPCFCs are needed.
\end{abstract}

\section{Introduction}

In recent years, three major alterations in the perception of gluten toxicity and $\mathrm{CD}$ have occurred. Firstly, the definition of $\mathrm{CD}$ has evolved with the advent of new testing strategies, and a broader view of $\mathrm{CD}$ has been brought forward, encompassing non-classic CD presentations increasingly seen both in adults and in children [1]. Secondly, the diagnostic approach to $\mathrm{CD}$ has changed, with the appearance of new diagnostic guidelines [2], which in selected cases of children and adolescents give the opportunity to make the diagnosis of $\mathrm{CD}$ without a duodenal biopsy [3]. Other new guidelines directed particularly at adults keep the duodenal biopsy as an essential part of the diagnosis [4]. Thirdly, the concept of NCGS has emerged. In the public, an increasing percentage of otherwise-healthy individuals in Europe, the US, and Australasia have adopted a gluten-free diet as part of their lifestyle [5], suggesting_but in no way provingthat NCGS is a real entity. This article will discuss the features that separate NCGS from CD and investigate the evidence base for the presence of NCGS, including studies that support NCGS as well as studies that stress the limitations of NCGS (Table 1). Lastly, we will give a framework for the way ahead.

\section{Definitions}

CD may be defined as a chronic small intestinal immunemediated enteropathy precipitated by exposure to dietary gluten in genetically predisposed individuals [6]. The old definitions included the term typical versus atypical, which now is discouraged, and the term latent $\mathrm{CD}$, which also is discouraged. CD is characterized by positivity of immunoglobulin A (IgA) tissue transglutaminase 2 (TG2) antibodies in serum, which is currently the most powerful screening test for CD. The presence of HLA-DQ2 $\left(\mathrm{DQA} 1{ }^{*} 0501,{ }^{*} 0505\right)$ or HLA-DQ8 (DQB1*0201, *0202) may support the CD diagnosis, but in most Western populations these HLA types exist in 25\% to 30\% of healthy subjects. Conversely, the absence of these HLA types is a very strong negative predictor for $\mathrm{CD}$, particularly useful in those already on a gluten-free diet. Still, the characteristic findings in the duodenal mucosa with crypt hypertrophy and villous atrophy [7] form a mainstay in the diagnosis. In the spectrum of histological changes, it is 
Table I. Clinical entities that may include toxicity toward gluten

\begin{tabular}{llll}
\hline Entity & Presumed prevalence & Biomarker & Final diagnosis \\
\hline Celiac disease & $1 \%$ & TG2-lgA & Biopsy \\
NGCS & $?$ & None & DBPCFC \\
Wheat allergy & $0.1 \%$ & IgE antibody & lgE + DBPCFC \\
\hline
\end{tabular}

Abbreviations: DBPCFC, double-blind placebo-controlled food challenge; Ig, immunoglobulin; NCGS, non-celiac gluten sensitivity; TG2, transglutaminase.

the presence of villous atrophy that is most indicative of $\mathrm{CD}$, whereas crypt hypertrophy alone or intraepithelial lymphocytosis is much less predictive of CD. Indeed, intraepithelial lymphocytosis is more common in other non-gluten-related conditions and in clinically normal subjects [8]. Wheat allergy is a distinct entity, characterized by an IgE-mediated response to wheat. Non-IgE-mediated reactivity has also been described [9].

\section{Characteristics of non-celiac gluten sensitivity}

NCGS should largely be considered only when tests for $\mathrm{CD}$ are negative, absent TG2-IgA on a normal diet, absence of the dependence of HLA DQ2 or DQ8, which may be slightly increased in patients with NCGS. Also, the characteristic histological findings in the duodenal mucosa are absent. As to the distinction from wheat allergy, IgE-wheat antibodies are absent in NCGS. The symptoms of NCGS most resemble those of irritable bowel syndrome (IBS) with bowel movement and abdominal pain [9] (Figure 1). NCGS has been claimed to be a cause of psychiatric conditions, including autism and schizophrenia [10-12]. Proving the role of gluten or even wheat in the genesis of symptoms has been challenging. DBPCFCs with gluten/wheat have been used to document NCGS (or non-celiac wheat sensitivity) in adult patients [13]. Their patient population was retrospectively collected within the out-patient group of IBS, and the authors performed DBPCFCs with wheat in a total of 276 patients. Gluten sensitivity was documented by subject report of symptoms by using a visual analogue score (VAS) rather than objective findings. With a similar design, an Australian group performed DBPCFCs in a group of patients who claimed gluten sensitivity, again based on a VAS. The group saw a clear dependency of wheat in the data [14]. However, in a follow-up study, the research group was able to demonstrate that the active component of the sensitivity was not the gluten fraction of wheat but rather in the so-called FODMAPs (fermentable oligo-, di-, mono-saccharides and polyols) [15]. These data raise a general word of caution to the purity of the ingredients in the challenge material. Furthermore, they underscore the drawbacks of relying on subjective findings rather than on objective findings, which are sadly lacking for NCGS, even when challenges are carried out in a blinded fashion.

\section{Children}

In children, circumstantial evidence and retrospective data collected from hospital files suggest that a considerable proportion of children suspected of $\mathrm{CD}$, but without serological and histological evidence of $\mathrm{CD}$, may have NCGS. It may be difficult to use a VAS, in particular in younger children. One thorough study has been published [16]; however, to the best of our knowledge, no DBPCFCs have been performed in children with gastroenterological symptoms of NCGS. One study was performed in children with autism [12], which suggests that the symptoms may be ameliorated by a gluten-free diet.

\section{Pathophysiology}

Despite the popular interest in gluten and gluten-related disorders, studies of the biological mechanisms to support NCGS are scarce. Some reports have described increased cellularity in the intestinal mucosa and increased immune reactivity in the mucosa in patients with NCGS. In a Norwegian study, biopsy material from patients with NCGS was compared with material from patients with CD [17]. Production of cytokines-interferon-gamma (IFN- $\gamma$ ) and myxovirus resistance $\mathrm{A}(\mathrm{MxA})$ - was clearly increased in patients with $C D$, whereas a less marked change in the patients with NCGS was increased cellularity of CD3-positive $\mathrm{T}$ cells, with an increase in mRNA for IFN- $\gamma$ after challenge with gluten. Amylase trypsin inhibitors (ATIs) have been identified in wheat as potent stimulators of innate immune reactions, notably the stimulation of Toll-like receptor 4 (TLR4) in monocytes, macrophages, and dendritic cells, which release a number of cytokines, including interleukin-8 (IL-8) and tumor necrosis factor-alpha (TNF- $\alpha$ ), in blood from patients with $\mathrm{CD}$ as well as healthy subjects and in intestinal biopsies from patients with CD [18]. These data suggest an activation avenue that applies both to CD as well as to NCGS or other inflammatory conditions. However, no further documentation that ATIs are involved in NCGS has been provided.

\section{The way ahead}

As no consistent biomarkers are available for NCGS, the diagnosis must rely on clinical symptoms and signs (for example, with a VAS) but preferably with objective findings. Such a diagnosis should be based on DBPCFC, 
Figure I. Possible relations between different disease entities with reactivity against gluten

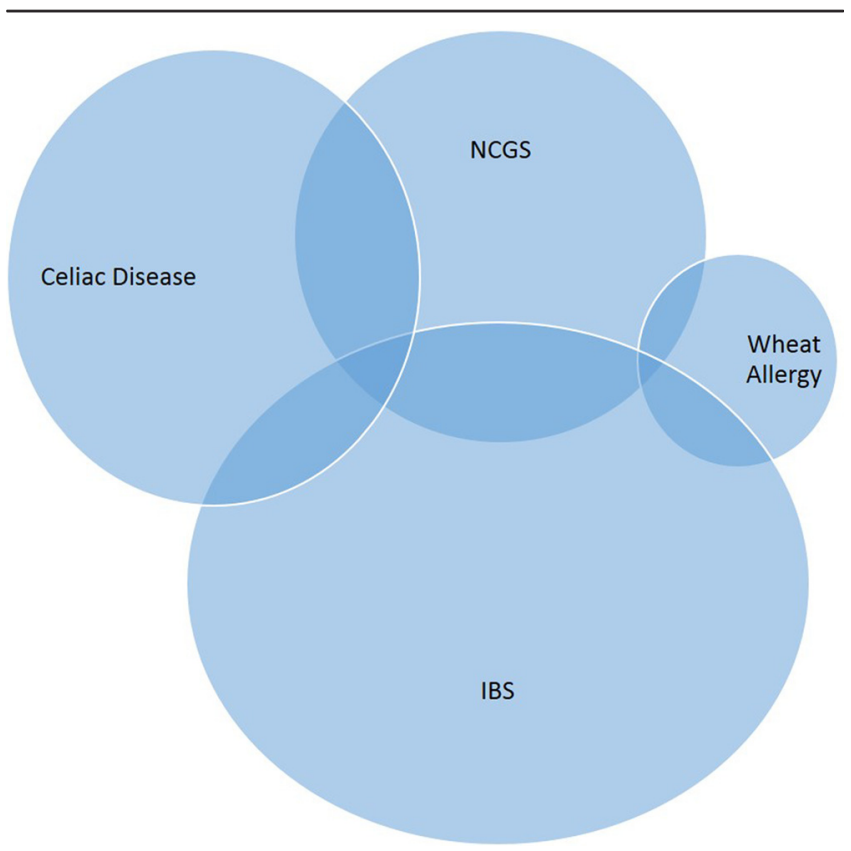

Abbreviations: IBS, irritable bowel syndrome; NCGS, non-celiac gluten sensitivity.

except in infants and small children. DBPCFC is an established procedure that is extensively used for food allergy in general [19]. The caveat in this approach is that, whereas symptoms of food allergy typically occur within the first few minutes to hours to days after the specific challenge, the symptoms of NCGS may occur after a longer time period. These time limits have not been firmly delineated. Furthermore, the dose of gluten should equal the doses ingested in the daily food. In theory, the DBPCFC should be repeated at least twice to minimize the risk of positivity based simply on chance. It must be kept in mind that, in patients who suspect themselves of food allergy, only roughly one out of three actually has a reproducible reaction toward the suspected food [20], and similar numbers of positivity (or even lower) may be found for NCGS. Certainly, a way ahead is to learn from our allergology colleagues to be proficient in DBPCFC as well as develop convenient new practical designs of DBPCFC and at the same time continue the search for accurate biomarkers.

\section{Abbreviations}

ATI, amylase trypsin inhibitor; CD, celiac disease; DBPCFC, double-blind placebo-controlled food challenge; IBS, irritable bowel syndrome; IFN- $\gamma$, interferon-gamma; Ig, immunoglobulin; NCGS, non-celiac gluten sensitivity; TG2, transglutaminase 2; VAS, visual analogue score.

\section{Competing interests}

Steffen Husby has participated in an advisory board with Tillotts Pharma, has acted as a speaker for Thermo Fisher Scientific, and has received grant support from The Danish Strategic Research Council, The Region of Southern Denmark, and Odense University Hospital Research Funds. Joseph Murray has received grant support from Alba Therapeutics, Alvine Pharmaceuticals, Inc., and the National Institutes of Health. He serves on the advisory board of Alvine Pharmaceuticals, Inc. and is a consultant to AMAG Pharmaceuticals, Entera Health, Inc., Glenmark, Sonomaceuticals, LLC, BioLineRx, GlaxoSmithKline, and Genentech. He has a patent with Miomics and receives royalties from Torax Medical, Inc. He received payment for development of educational presentations from the National Foundation for Celiac Awareness.

\section{References}

I. Garampazzi A, Rapa A, Mura S, Capelli A, Valori A, Boldorini R, Oderda G: Clinical pattern of celiac disease is still changing. J Pediatr Gastroenterol Nutr 2007, 45:6I I-4.

\section{FIOOOPrime}

2. Husby S, Koletzko S, Korponay-Szabó IR, Mearin ML, Phillips A, Shamir R, Troncone R, Giersiepen K, Branski D, Catassi C, Lelgeman M, Mäki M, Ribes-Koninckx C, Ventura A, Zimmer KP: European Society for Pediatric Gastroenterology, Hepatology, and Nutrition guidelines for the diagnosis of coeliac disease. J Pediatr Gastroenterol Nutr 2012, 54:136-60.

3. Hill PG, Holmes GKT: Coeliac disease: a biopsy is not always necessary for diagnosis. Aliment Pharmacol Ther 2008, 27:572-7.

\section{FlOOOPrime
RECOMMENDED}

4. DiGiacomo DV, Tennyson CA, Green PH, Demmer RT: Prevalence of gluten-free diet adherence among individuals without celiac disease in the USA: results from the Continuous National Health and Nutrition Examination Survey 20092010. Scand J Gastroenterol 2013, 48:921-5.

\section{FlOOOPrime}

\section{RECOMMENDED}

5. Rubio-Tapia A, Hill ID, Kelly CP, Calderwood AH, Murray JA: ACG clinical guidelines: diagnosis and management of celiac disease. Am J Gastroenterol 2013, 108:656-76; quiz 677.

6. Ludvigsson JF, Leffler DA, Bai JC, Biagi F, Fasano A, Green, Peter HR, Hadjivassiliou M, Kaukinen K, Kelly CP, Leonard JN, Lundin, Knut Erik Aslaksen, Murray JA, Sanders DS, Walker MM, Zingone F, Ciacci C: The Oslo definitions for coeliac disease and related terms. Gut 2013, 62:43-52.

FlOOOPrime
RECOMMENDED

7. Oberhuber G, Granditsch G, Vogelsang H: The histopathology of coeliac disease: time for a standardized report scheme for pathologists. J Gastroenterol Hepatol 1999, I I: I I85-94.

8. Pellegrino S, Villanacci V, Sansotta N, Scarfi R, Bassotti G, Vieni G, Princiotta A, Sferlazzas C, Magazzù G, Tuccari G: Redefining the intraepithelial lymphocytes threshold to diagnose gluten sensitivity in patients with architecturally normal duodenal histology. Aliment Pharmacol Ther 20I I, 33:697-706.

9. Sanders DS, Aziz I: Non-celiac wheat sensitivity: separating the wheat from the chat!. Am J Gastroenterol 2012, 107:1908-12. 
10. Potkin SG, Weinberger D, Kleinman J, Nasrallah $H$, Luchins $D$, Bigelow L, Linnoila M, Fischer SH, Bjornsson TD, Carman J, Gillin JC, Wyatt RJ: Wheat gluten challenge in schizophrenic patients. Am J Psychiatry 1981, 138: I208-II.

II. Magistris L de, Picardi A, Siniscalco D, Riccio MP, Sapone A, Cariello R, Abbadessa S, Medici N, Lammers KM, Schiraldi C, lardino P, Marotta R, Tolone C, Fasano A, Pascotto A, Bravaccio C: Antibodies against food antigens in patients with autistic spectrum disorders. Biomed Res Int 2013, $2013: 729349$.

12. Whiteley P, Haracopos D, Knivsberg A, Reichelt KL, Parlar S, Jacobsen J, Seim A, Pedersen L, Schondel M, Shattock P: The ScanBrit randomised, controlled, single-blind study of a gluten- and casein-free dietary intervention for children with autism spectrum disorders. Nutr Neurosci 20I0, 13:87-I00.

13. Carroccio A, Mansueto P, lacono G, Soresi M, D'Alcamo A, Cavataio F, Brusca I, Florena AM, Ambrosiano G, Seidita A, Pirrone G, Rini GB: Non-celiac wheat sensitivity diagnosed by double-blind placebo-controlled challenge: exploring a new clinical entity. Am J Gastroenterol 20I2, 107:1898-906; quiz 1907.

\section{FlOOOPrime RECOMMENDED}

14. Biesiekierski JR, Newnham ED, Irving PM, Barrett JS, Haines M, Doecke JD, Shepherd SJ, Muir JG, Gibson PR: Gluten causes gastrointestinal symptoms in subjects without celiac disease: a double-blind randomized placebo-controlled trial. Am J Gastroenterol 20II, 106:508-14; quiz 5I5.

15. Biesiekierski JR, Peters SL, Newnham ED, Rosella O, Muir JG, Gibson PR: No effects of gluten in patients with self-reported non-celiac gluten sensitivity after dietary reduction of fermentable, poorly absorbed, short-chain carbohydrates. Gastroenterology 2013, 145:320-8.el-3.

16. Francavilla R, Cristofori F, Castellaneta S, Polloni C, Albano V, Dellatte S, Indrio F, Cavallo L, Catassi C: Clinical, serologic, and histologic features of gluten sensitivity in children. J Pediatr 20I4, I64:463-7.el.

FlOOOPrime
RECOMMENDED

17. Brottveit M, Beitnes AR, Tollefsen S, Bratlie JE, Jahnsen FL, Johansen F, Sollid LM, Lundin, Knut E A: Mucosal cytokine response after short-term gluten challenge in celiac disease and non-celiac gluten sensitivity. Am J Gastroenterol 2013, 108:842-50.

\section{FlOOOPrime} RECOMMENDED

18. Junker $Y$, Zeissig S, Kim S, Barisani D, Wieser H, Leffler DA, Zevallos V, Libermann TA, Dillon S, Freitag TL, Kelly CP, Schuppan D: Wheat amylase trypsin inhibitors drive intestinal inflammation via activation of toll-like receptor 4. J Exp Med 2012, 209:2395-408.

\section{FlOOOPrime}

RECOMMENDED

19. Bock SA, Sampson HA, Atkins FM, Zeiger RS, Lehrer S, Sachs M, Bush RK, Metcalfe DD: Double-blind, placebo-controlled food challenge (DBPCFC) as an office procedure: a manual. J Allergy Clin Immunol Pract 1988, 82:986-97.

20. Goldman AS, Anderson DW, Sellers WA, Saperstein S, Kniker WT, Halpern SR: Milk allergy I. Oral challenge with milk and isolated milk proteins in allergic children. Pediatrics 1963, 32:425-43. 